\title{
Analysis, evaluation and adaptation of the ReTransQoL: a specific quality of life questionnaire for renal transplant recipients
}

Davy Beauger ${ }^{1 *}$, Stéphanie Gentile ${ }^{1,2}$, Elisabeth Jouve ${ }^{2}$, Bertrand Dussol ${ }^{3}$, Christian Jacquelinet ${ }^{4}$ and Serge Briançon ${ }^{5,6}$

\begin{abstract}
Background: End stage renal disease (ESRD) profoundly impacts the lives of patients. Kidney transplantation provides the greatest health-related quality of life (HRQOL) improvement. Its measurement has become an important outcome parameter and a very important criterion in the evaluation of any type of medical treatment, especially in the field of renal transplantation.

In 2007, a specific self-administered questionnaire for renal transplant recipients was developed in the French language: the ReTransQol (RTQ).

After 5 years of use, the properties of the RTQ needed to be re-evaluated in a larger sample.

This paper describes the analysis of the ReTransQol and its adaptation to achieve an improved and revised version.

Methods: The study design included three analysis phases for two samples of adult renal transplant recipients which came from two cross-sectional multicenter studies carried out in France in 2007 and 2012. Psychometrics properties like construct validity, acceptability and feasibility, reliability and convergent validity were evaluated and every analysis resulted in a new version of the questionnaire: the RTQ V2. The construct validity of the new RTQ was assessed with a Confirmatory Factor Analysis on a large sample of patients.

Results: The study samples included 1,059 patients and 1,591 patients, respectively.

After a principal component analysis, item reduction was performed and a total of 13 items were deleted. A final version of the RTQ V2 was created and comprised of 32 items describing 5 domains: Physical Health, Social Functioning, Medical Care, Treatment and Fear of Losing Graft.

The explained variance between the first and second RTQ versions improved from $46.3 \%$ to $53.1 \%$. All psychometric properties of RTQ V2 were satisfactory: IIC $>0.4$, IDV (\%) of $100 \%$ and Cronbach's Alpha $>0.7$ in every dimension. The confirmatory analysis showed that the overall scalability of the RTQ V2 was satisfactory; all items showed a good fit to the Rasch model within each dimension, and showed INFIT statistics inside the acceptable range.
\end{abstract}

Conclusions: Psychometric properties allow this new version of the questionnaire to be used to assess different specific dimensions for the renal transplant population, more effectively than previously possible.

Keywords: Quality of life, Medical outcomes, Specific questionnaire, Renal transplantation, RETRANSQOL

\footnotetext{
* Correspondence: davy.beauger@ap-hm.fr

${ }^{1}$ Faculté de Médecine, Laboratoire de Santé Publique, Université Aix-Marseille, Marseille EA 3279, France

Full list of author information is available at the end of the article
} 


\section{Introduction}

End stage renal disease (ESRD) profoundly impacts the lives of patients, leading to activity limitations, social participation restrictions, and dependence caused by the need for renal replacement therapy (RRT) [1-5]. It also represents a significant burden to society caused by the high treatment costs and an increasing prevalence of ESRD [6-9].

The number of patients being treated for ESRD globally was estimated to be 2,786,000 at the end of 2011, and with a 6-7\% growth rate, continues to increase at a significantly higher rate than the world population. Of these ESRD patients, approximately 2,164,000 were undergoing dialysis treatment and around 622,000 were living with kidney transplants [10].

In France, between 9,000 and 10,000 new patients with chronic renal failure required the initiation of RRT in 2010, and about 67,000 were treated for renal failure, including approximately 30,000 transplants [11].

As ESRD reduces life expectancy, renal transplantation has become worldwide the treatment of choice over hemodialysis, which remains the only treatment for the majority of patients [12-14]. The aim of renal transplantation is not only to improve renal function, but also to enhance the patient's ability to enjoy life as fully as possible. Kidney transplantation also provides the greatest improvement for health-related quality of life (HRQOL), whose measurement has become an important outcome parameter [15-17]. HRQOL has become a very important criterion in the evaluation of any type of medical treatment [18], especially in the field of renal transplantation, and is associated with the improvement of graft survival [19-22]. Several determinations of HRQOL focus on physical status and symptoms, functional status, mental health, social functioning, and general health perceptions.

Currently, few specific HRQOL questionnaires have been developed for renal transplant recipients and few are validated or available in French [23,24]. Among questionnaires adapted to the general population, the Short Form-36 Health Survey (SF-36) remains the most widely used in quality of life studies [25-27].

In 2007, a specific self-administered questionnaire for renal transplant recipients (RTR) was developed by Gentile et al. in the French language: the ReTransQol (RTQ) [28]. The RTQ was validated in a study of 335 French patients randomly selected from the registry of the transplant center in Marseille.

After 5 years of use in many French studies [29,30], the properties of the RTQ needed to be re-evaluated in a larger sample. In fact, the RTQ has been validated but not established with a Confirmatory Factor Analysis, and the psychometric properties can be improved. Moreover, the questionnaire seems to be slightly lengthy, and can be better adapted for routine use.

This paper describes the analysis of the ReTransQol and its adaptation, in order to achieve an improved and revised version.

\section{Methods}

The study design involved analysis of the original version of the ReTransQol (RTQ V1) and its adaptation, and included three phases for two samples of renal transplant recipients (Figure 1).

\section{Data sources}

For Phase 1 and Phase 2, both samples came from the same cross-sectional multicenter study, which was carried out in France between March 2007 and March 2008 in eight regions of France participating in the Renal Epidemiology and Information Network (REIN) in 2003.

For Phase 3, the sample came from a cross-sectional multicenter study (QUAVIREIN: French translation of Renal Quality of Life study) which was carried out in France between May 2011 and September 2012, in 21 regions of France participating in the REIN network in 2010 and whose register was complete and exhaustive.

\section{Participants}

For each sample, all participants were RTR over 18 years of age with a functioning graft for at least one year. Multi-organ transplant patients before or simultaneously with their kidney transplant were excluded. The samples were stratified by regions and age class, using the same sampling rate for each stratum. The sample size was calculated to detect a difference of 5 points in the SF-36, considering a standard deviation of 20 , and assuming a two-sided level of $5 \%$ with $80 \%$ power. The sample size calculation was 1,000 patients for the first national study, and 1,500 for the QUAVIREIN study. Considering a nonresponse rate of approximately $30 \%$ for each study, 1,300 and 1,800 questionnaires were sent in order to achieve these objectives. The number of self-administered questionnaires returned was 1,059 for the first study and 1,591 for the second, with a response rate of over $70 \%$ for both.

\section{Data collection procedures for both studies}

The French version of the SF-36 [31] is a generic instrument, with scores ranging from 0 to 100 (worst to best possible HRQOL) for eight domains: physical functioning $(\mathrm{PF})$, role-physical (RP), bodily pain (BP), general health $(\mathrm{GH})$, vitality $(\mathrm{VT})$, social functioning $(\mathrm{SF})$, role-emotional (RE) and mental health $(\mathrm{MH})$.

The ReTransQol V1 [28] is a specific instrument consisting of 45 items describing 5 dimensions: physical health $(\mathrm{PH})$, mental health $(\mathrm{MH})$, medical care and satisfaction (MC), treatment (TR) and fear of losing the graft 


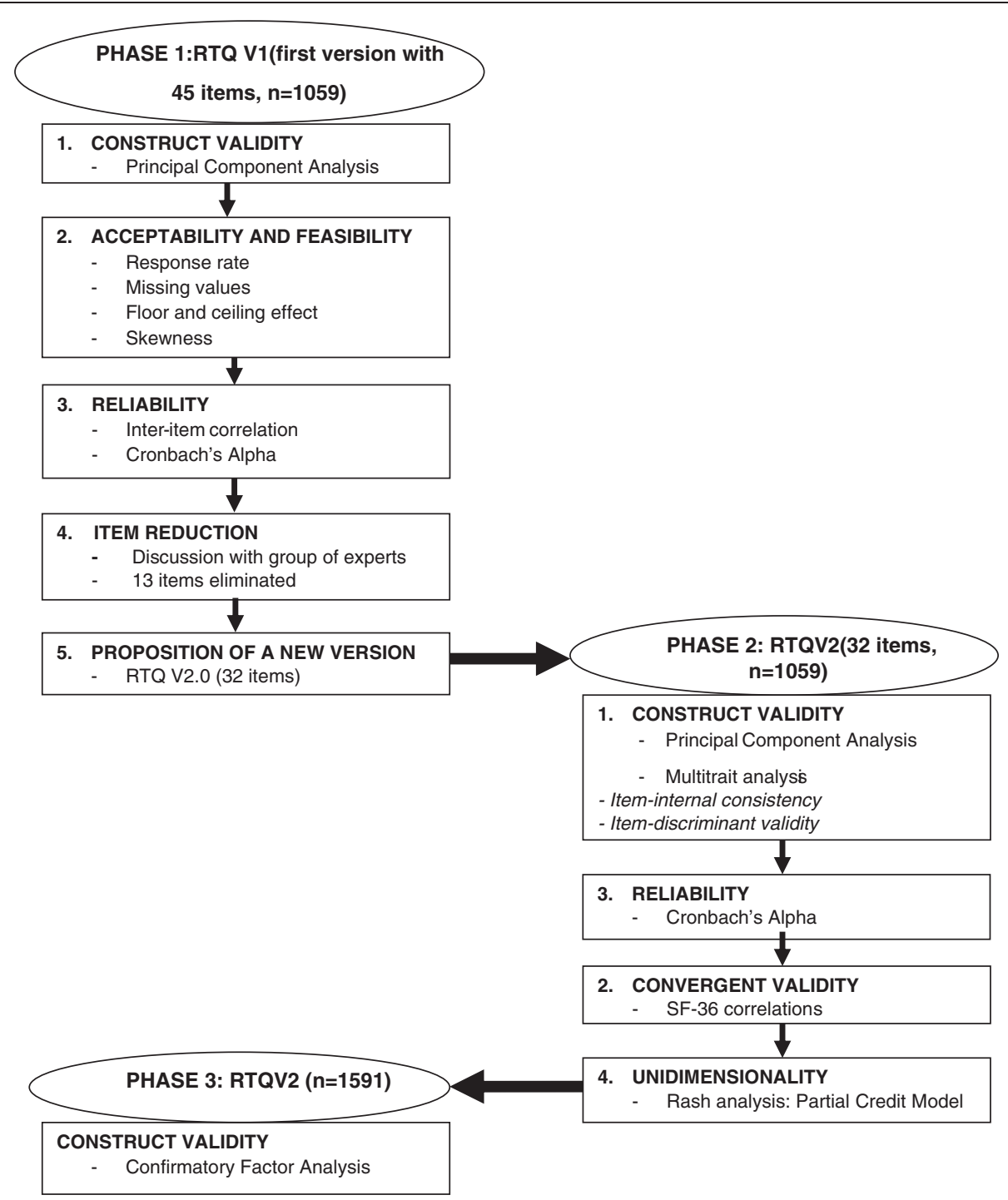

Figure 1 Study design: analysis and adaptation of the ReTransQoL questionnaire.

(FLG). Each score ranges from 0 to 100 and the higher the score, the better the perceived state of health. Data collection included demographic, socio-demographic and medical characteristics, as well as HRQOL. SF-36 and RTQ V1 (first version) were used to evaluate HRQOL for both studies. All measuring instruments were sent to the patient's home with a newsletter and an explanatory letter signed by the project coordinator. Patients returned the completed questionnaires via a pre-stamped envelope. Non-respondents were reminded by a second letter three weeks later and contacted by phone at the same time.

\section{Ethical aspects}

The studies' methodology was approved by the local Institutional Review Board, the Advisory Committee on Information Processing in Health Research (CCTIRS n 06-311 and no. 05-142) and the French consulting committee for treatment of information in health research (CNIL n ${ }^{\circ} 906248$ and CNIL $n^{\circ} 905263$ ), which ensures the confidentiality of all information collected.

\section{Statistical analysis}

During the first phase, the construct validity and dimensional structure of the questionnaire were assessed by studying principal component factor analyses with Varimax rotation. Prior to the extraction of the factors, several tests were used to assess the suitability of the respondent data for factor analysis. These tests included KaiserMeyer-Olkin (KMO) Measure of Sampling Adequacy and Bartlett's Test of Sphericity. The KMO index ranges from 0 to 1 , with 0.50 considered to be suitable for factor 
Table 1 Socio-demographic comparison between the two samples used

\begin{tabular}{|c|c|c|c|c|}
\hline & & Population $1 \mathrm{~N}=1059$ & Population $2 \mathrm{~N}=1591$ & Significance $^{*}$ \\
\hline \multicolumn{2}{|l|}{ Male } & $61.9 \%(n=656)$ & $60.5 \%(n=963)$ & $p=0.52$ \\
\hline \multicolumn{2}{|c|}{ Age (years), mean \pm standard deviation } & $55.2 \pm 12.4$ & $55.3 \pm 14.2$ & $\mathrm{p}=0.85$ \\
\hline Level of education & Secondary 1st stage (college \& high school) & $45.6 \%(n=483)$ & $45.3 \%(n=721)$ & $p=0.9$ \\
\hline \multirow[t]{2}{*}{ Employment status } & Employed & $35.5 \%(n=377)$ & $39.9 \%(n=635)$ & $p=0.007$ \\
\hline & Retired & $29.9 \%(n=317)$ & $36.1 \%(n=574)$ & $P<0.001$ \\
\hline
\end{tabular}

* Chi-square test for frequency comparison. Student $t$-test for mean comparisons.

analysis [32]. The Bartlett's Test of Sphericity should be significant $(\mathrm{p}<0.05)$ for factor analysis to be appropriate. Next, a Principal Component Analysis (PCA) of the RTQ V1 was assessed to analyze the structure of the questionnaire over a larger sample than during the phase of development and validation [33]. Each dimension was examined in order to indicate which items could potentially be deleted due to their low psychometric performance at a dimension level. This was done by studying the inter-item and inter-dimension correlations (Pearson's $r$ ). Items which loaded $<0.40$ for all the factors were considered as potentially removable.

Acceptability and feasibility were assessed regarding response rate, missing values, skewness, inter-item correlation and floor or ceiling effects. Items were eliminated during the reduction phase with missing values exceeding $5 \%$, high inter-item correlation $(r>0.80)$, floor or ceiling effects over $70 \%$, or an absolute value of skewness exceeding 4.0.

During the item reduction phase, the most clinically relevant items were kept and lowest items were eliminated after analysis and discussion with the group of experts.

This analysis resulted in a new version of the questionnaire: the RTQ V2.0.

During the second phase, the psychometric properties of the RTQ V2.0 were evaluated.

Another factor analysis (PCA) with the items retained was conducted to ensure the construct validity of the RTQ V2.0. The relevance of the grouping of items into the original structure isolated by PCA was examined using multitrait multi-item analyses [34], examining correlations between item scores and dimension scores. Item-internal consistency (IIC) was assessed by correlating each item with its dimension. Item-discriminant validity (IDV) was assessed by determining the extent to which items correlate more highly with dimensions they are hypothesized to represent than with different dimensions. Each item should be highly correlated with its scale, thus supporting item-internal consistency (IIC); a correlation corrected for overlap of at least 0.4 is recommended [35]. In addition, items should be more highly correlated with their own scale than with the other dimension scales (item-discriminant validity, IDV).

The internal consistency reliability of the RTQ was measured using Cronbach's alpha coefficients [36], which were computed to estimate the internal consistency reliability of each dimension score. A reliability of at least 0.70 is recommended to compare groups of patients [37].

The uni-dimensionality of the new version (RTQ V2.0) was assessed using Rasch analyses, the Partial Credit Model $[38,39]$. The scalability of each dimension's scale was assessed by the pattern of the item's goodness-of-fit statistics (INFIT). Items with INFIT included in the] $0.7 ; 1.3$ [interval were kept ensuring that all the items of the scale tended to measure the same concept.

External validity and convergent validity were explored by calculating Pearson's correlation coefficients between the RTQ scores and SF-36 scores. Dimensions measuring the same concept were expected to be correlated with each other.

Finally, we tested the scores of HRQOL of the RTQ V2.0 with comparisons of subgroups (sex and age class) to confirm good properties of measurement compared with results of other studies.

For the third phase, the construct validity was confirmed with a Confirmatory Factor Analysis (CFA) for the second

Table 2 Comparison of RTQ V1 scores between the two samples

\begin{tabular}{|c|c|c|c|c|c|}
\hline \multirow[b]{2}{*}{ Dimensions } & \multicolumn{2}{|c|}{ Population 1} & \multicolumn{2}{|c|}{ Population 2} & \multirow{2}{*}{$\begin{array}{c}T \text {-test } \\
\mathrm{p} \text {-value }\end{array}$} \\
\hline & $\mathbf{n}$ & mean $\pm S D(\min -\max )$ & $\mathrm{n}$ & mean $\pm S D(\min -\max )$ & \\
\hline $\mathrm{PH}$ & 1039 & $59.5 \pm 18.7(0-100)$ & 1573 & $58.8 \pm 19.0(0-100)$ & 0.34 \\
\hline MH & 1042 & $77.1 \pm 19.3(0-100)$ & 1571 & $76.5 \pm 19.0(4.8-100)$ & 0.45 \\
\hline MC & 1027 & $72.7 \pm 17.6(0-100)$ & 1572 & $72.3 \pm 17.8(0-100)$ & 0.61 \\
\hline TR & 1030 & $79.0 \pm 15.9(25-100)$ & 1575 & $75.8 \pm 17.8(8.3-100)$ & $<0.001$ \\
\hline FLG & 1042 & $58.4 \pm 20.4(0-100)$ & 1566 & $59.8 \pm 19.5(0-100)$ & 0.07 \\
\hline
\end{tabular}

SD, standard deviation; $P H$, Physical health; $M H$, Mental health; MC, Medical care and satisfaction; TR, Treatment; FG, Fear of losing graft. 
sample of 1,591 patients. Robust maximum likelihood Confirmatory Factor Analysis was performed to test the fit to the model assessed by the computation of the root mean square error of approximation (RMSEA: $<0.05$, good fit; $0.05-0.08$, fair or reasonable; $>0.08$ unsatisfactory fit), the comparative fit index (CFI), the Standardized Root Mean Square Residual (SRMR) and the Goodness of Fit Index (GFI) [34,40]. The CFI and the GFI are expected to be greater than 0.9 if the fit is adequate and the SRMR must be close to 0 [41-43]. All correlations between each dimension and its items were extracted from the CFA.

Data analyses were performed using SPSS 19.0, Winstep and LISREL softwares.

\section{Results}

The study sample for the first two phases included 1,059 patients; 1,591 patients were enrolled in the third phase. The data set was jointly normally distributed.

The characteristics of the two samples (Table 1) and the HRQOL scores (Table 2) were not significantly different, except concerning the second sample where the proportion of retired patients was slightly higher and the "treatment dimension" which was slightly lower.

For the first phase, the PCA of the RTQ V1 showed an unsatisfactory structure of the items with the dimensions, with a KMO of 0.841 . The 5 dimensions were confirmed with a variance of about $50 \%$, but several items were not classified in the appropriate component and had a low psychometric performance $(<0.40)$. At the end of this step, 10 items were removed (Table 3 ).

The analysis of the response rate, the inter-item correlation and the floor and ceiling effects allowed us to remove 3 more items for which the response rate was $<30 \%$, interitem correlation was 0.845 , and a ceiling effect of $>70 \%$. Item reduction was performed at the end of the first step, where a total of 13 items were removed (Table 3 ). The iterative process of item selection resulted in a final version of the RTQ V2.0 comprised of 32 items describing 5 domains: Physical Health, Social Functioning, Medical Care, Treatment and Fear of Losing Graft (Table 4). The set of the 32 items kept and the 13 items deleted was

Table 3 Number of items deleted according to dimensions and versions of RTQ

\begin{tabular}{cccc}
\hline & RTQ V1 & RTQ V2 & Items deleted \\
\hline Dimensions & $\mathrm{PH}=10$ & $\mathrm{PH}=8$ & 2 \\
& $\mathrm{MH}=9$ & $\mathrm{SF}=5$ & 4 \\
& $\mathrm{MC}=11$ & $\mathrm{MC}=8$ & 3 \\
& $\mathrm{TR}=9$ & $\mathrm{TR}=5$ & 4 \\
Total & $\mathrm{FLG}=6$ & $\mathrm{FLG}=6$ & 0 \\
\hline
\end{tabular}

$P H$, Physical health; $M H$, Mental health; $M C$, Medical care and satisfaction; $S F$, Social functioning; $T R$, Treatment; $F G$, Fear of losing graft.
Table 4 Principal component analysis of the RTQ V2 with Varimax rotation $(n=1059)$

\begin{tabular}{|c|c|c|c|c|c|c|}
\hline & \multicolumn{5}{|c|}{ Component } & \multirow[t]{2}{*}{ Total variance } \\
\hline & 1 & 2 & 3 & 4 & 5 & \\
\hline$\%$ of variance & 23.8 & 11.7 & 6.7 & 6.1 & 4.8 & 53.1 \\
\hline Item number & & & & & & Dimension Labels \\
\hline $\mathrm{q} 1$ & .645 & & & & & Physical Health \\
\hline q3 & .682 & & & & & \\
\hline $\mathrm{q} 4$ & .567 & & & & & \\
\hline q5 & .720 & & & & & \\
\hline q6 & .602 & & .303 & & & \\
\hline q7 & .618 & & & & & \\
\hline q8 & .663 & & & & & \\
\hline q9 & .708 & & & & & \\
\hline$q 40$ & & .770 & & & & Medical Care \\
\hline $\mathrm{q} 41$ & & .670 & & & & \\
\hline$q 42$ & & .819 & & & & \\
\hline$q 43$ & & .849 & & & & \\
\hline$q 44$ & & .730 & & & & \\
\hline q45 & & .672 & & & & \\
\hline q46 & & .729 & & & & \\
\hline q49 & & .761 & & & & \\
\hline q15 & & & .525 & & & Fear of losing graft \\
\hline q16 & & & .615 & & & \\
\hline q29 & & & .642 & & & \\
\hline q30 & & & .694 & & & \\
\hline q31 & & & .759 & & & \\
\hline q32 & & & .740 & & & \\
\hline$q 19$ & & & & .833 & & Social Functioning \\
\hline $\mathrm{q} 20$ & & & & .737 & & \\
\hline q21 & & & & .596 & & \\
\hline $\mathrm{q} 22$ & & & & .595 & & \\
\hline $\mathrm{q} 28$ & & & & .604 & & \\
\hline$q 11$ & & .363 & & & .544 & Treatment \\
\hline $\mathrm{q} 17$ & & & & & .336 & \\
\hline q37 & & & & & .758 & \\
\hline q38 & & & .301 & & .682 & \\
\hline q39 & & & & & .750 & \\
\hline
\end{tabular}

discussed by a pluridisciplinary group (nephrologists, interviewers, and methodologists), who accepted and validated the modifications.

For the 2nd phase, the Kaiser-Meyer-Olkin Measure of Sampling Adequacy $(\mathrm{KMO}=0.880)$ and Bartlett's Test of Sphericity $(\mathrm{p}<0.01)$ were also used to assess the suitability of the respondent data for factor analysis. The structure of the 5 factors was fixed and supported by PCA with Varimax rotation and accounted for $53.1 \%$ of the total 
variance (Table 4). The inter-dimension correlations were all significant $(\mathrm{p}<0.001)$ and ranged from $\mathrm{r}=0.16$ for $\mathrm{MC}$ with FLG dimension, to $\mathrm{r}=0.43$ for $\mathrm{PH}$ with TR dimension. All other inter-dimension correlations were between $r=0.27$ and $r=0.38$.

The correlation between each item and its contributive dimension was higher than the correlation with other dimensions. Internal consistency was acceptable for each dimension (>0.4). Item-discriminant validity (IDV) results were acceptable for every dimension of the RTQ (IDV < IIC ranges). The floor effect ranged from $0 \%$ to $0.7 \%$, and the ceiling effect ranged from $0.6 \%$ to $11.7 \%$. Cronbach's alpha was $>0.7$ in every dimension ( 0.7 to 0.9$)$, satisfying the internal consistency reliability.

Finally, the overall scalability of the RTQ was satisfactory; all items showed a good fit to the Rasch model within each dimension, and showed INFIT statistics inside the acceptable range $(0.7-1.3)$. The dimension scales' characteristics are summarized in Table 5.

The results of the convergent validity of the RTQ V2.0 with SF36 dimensions are shown in Table 6. The PH dimension of the RTQ showed high correlations with Vitality, General Health, Physical Functioning and Bodily Pain $(r>0.6)$. The new SF dimension (previously $\mathrm{MH}$ ) of the RTQ V2.0 was correlated with Mental Health and Social Functioning.

However, the specific MC dimension was globally uncorrelated or was weakly correlated with the SF36 dimensions $(r<0.3)$. The highest correlations of the TR dimension of the RTQ were with Vitality and General Health. Finally, the FLG dimension was best correlated with General Health and Mental Health.

Comparisons of HRQOL scores of different demographic subgroups (Table 7) showed that women have lower scores in comparison with men in every dimension $(\mathrm{p}<0.05)$. Three dimensions differed according to age: $\mathrm{PH}(\mathrm{p}=0.002)$, MC $(p=0.009)$ and FLG $(p=0.019)$. The PH dimension score is lower between patients $>65$ years and 35-50 years (post hoc Bonferoni test; $\mathrm{p}=0.003$ ). In contrast, the MC and the FLG dimensions were lower between patients $<35$ years than $>65$ years (post hoc Bonferoni test; $\mathrm{p}=0.04$ and $\mathrm{p}=0.01$ ).
Table 6 Correlation between SF36 and RTQ V2 scores

\begin{tabular}{cccccc}
\hline & PH & SF & MC & TR & FLG \\
\hline Physical functioning & $\mathbf{. 6 8 2}$ & .227 & .141 & .217 & .229 \\
Role limitations due to physical health & .595 & .237 & .098 & .269 & .192 \\
Bodily pain & $\mathbf{. 6 6 8}$ & .229 & .149 & .326 & .236 \\
Mental health & .560 & $\mathbf{. 5 1 6}$ & .297 & .394 & $\mathbf{. 4 3 0}$ \\
Role limitations due to & .494 & .328 & .127 & .263 & .231 \\
emotional problems & & & & & \\
Social functioning & .556 & $\mathbf{. 4 6 5}$ & .251 & .398 & .340 \\
$\quad$ Vitality & $\mathbf{. 7 8 1}$ & .340 & .306 & $\mathbf{. 4 0 2}$ & .339 \\
General health & $\mathbf{. 7 0 4}$ & .304 & .289 & $\mathbf{. 4 7 0}$ & $\mathbf{. 4 6 2}$
\end{tabular}

$P H$, Physical health, $S F$, Social functioning; $M C$, Medical care and satisfaction; $T R$, Treatment; FG, Fear of losing graft; Data are pearson's $r$ correlation coefficient; significance of correlation coefficient tests were $p<0.01$ for all correlations. Bold characters indicate main correlation between RTQ and SF36 dimension.

In the third and last phase, the structure of the RTQ V2.0 was established with a confirmatory factor analysis providing satisfactory indicators: RMSEA $=0.05$, SRMR = $0.049, \mathrm{CFI}=0.97$ and GFI $=0.91$. Strongest correlations of each item in their own dimension and between dimensions are shown in Figure 2 and highlighted in bold.

\section{Discussion}

This paper describes the analysis, item reduction, and validation of a specific self-administered instrument assessing the HRQOL of renal transplant recipients: The ReTransQol (RTQ).

First, we analyzed the structure of the RTQ V1 over a sample of 1,059 RTR from a French cross-sectional multicenter study carried out between March 2007 and March 2008. Our sample size was much larger than those used in other studies to develop HRQOL's questionnaires, and larger than the first validation of the RTQ (1,059 vs. 355 patients). The construct validity of the RTQ V1 was supported by principal component analysis and showed an unsatisfactory structure, with some correlations below 0.3. However, five dimensions were confirmed by the results of the PCA. At the end of the first phase of the study, 13 items were removed (Table 3 ) to obtain a better version of the RTQ: the RTQ V2.0. Some items from the

Table 5 Dimensions characteristics of the 32-item 2nd version of the ReTransQol $(n=1059)$

\begin{tabular}{ccccccccc}
\hline RTQ dimension (number of items) & Mean \pm SD & IIC & IDV & MV (\%) & Floor (\%) & Ceiling (\%) & Cronbach's a & INFIT \\
\hline PH (8) & $59.5 \pm 18.7$ & $0.61-0.75$ & $0.09-0.44$ & 1.9 & 0.1 & 0.6 & $0.81-1.3$ \\
SF (5) & $77 \pm 19.3$ & $0.65-0.77$ & $0.11-0.35$ & 1.6 & 0.3 & 11.7 \\
MC (8) & $72.7 \pm 17.6$ & $0.71-0.84$ & $0.09-0.33$ & 3 & 0.3 & 0.74 \\
TR (5) & $79 \pm 15.8$ & $0.42-0.76$ & $0.10-0.40$ & 2.7 & 0.7 & 0.9 & 0.6 & $0.74-1.3$ \\
FLG (6) & $58.4 \pm 20.4$ & $0.60-0.74$ & $0.01-0.40$ & 1.6 & 0 & 0.7 & 0.9 & $0.78-1.29$ \\
\hline
\end{tabular}

PH, Physical health; SF, Social functioning; MC, Medical care and satisfaction; TR, Treatment; FG, Fear of losing graft; IIC, item-internal consistency (min-max of Pearson's $r$ correlation coefficient); IDV, item-discriminant validity (min-max of Pearson's $r$ correlation coefficient); MV, percentage of missing values; Floor, floor effect (\%); Ceiling, ceiling effect (\%); Cronbach's a, Cronbach's alpha consistency coefficient; INFIT, min-max Rasch statistics. 
Table 7 HRQOL scores of the RTQ V2 for renal transplant recipients according to gender and age class

\begin{tabular}{|c|c|c|c|c|c|c|c|}
\hline & & & $\mathrm{PH}$ & MH & MC & TR & FLG \\
\hline \multirow[t]{5}{*}{ Gender } & Men & $n$ & 643 & 645 & 633 & 635 & 643 \\
\hline & & Mean \pm SD & $62 \pm 17.6$ & $79.2 \pm 17.5$ & $74.1 \pm 17$ & $79.8 \pm 16$ & $60.3 \pm 19.7$ \\
\hline & Women & $n$ & 396 & 397 & 394 & 395 & 399 \\
\hline & & Mean \pm SD & $55.4 \pm 19.7$ & $73.6 \pm 21.5$ & $70.4 \pm 18.3$ & $77.8 \pm 15.5$ & $55.2 \pm 21$ \\
\hline & $t$-test & $p$-value & $p<0.001$ & $p<0.001$ & $p<0.001$ & $p=0.04$ & $p<0.001$ \\
\hline \multirow[t]{9}{*}{ Age } & Less than 35 years & $n$ & 67 & 67 & 65 & 65 & 66 \\
\hline & & Mean \pm SD & $62.6 \pm 16.8$ & $81.2 \pm 15.3$ & $68.1 \pm 18.1$ & $75.8 \pm 15.7$ & $51.9 \pm 22.3$ \\
\hline & 35 to 50 years & $n$ & 267 & 270 & 269 & 269 & 269 \\
\hline & & Mean \pm SD & $62.6 \pm 17$ & $75.9 \pm 20.4$ & $70.7 \pm 17.6$ & $77.9 \pm 15.9$ & $58.2 \pm 19.4$ \\
\hline & 50 to 65 years & $n$ & 473 & 475 & 468 & 469 & 475 \\
\hline & & Mean \pm SD & $58.7 \pm 19.2$ & $76.3 \pm 19.6$ & $73.4 \pm 18$ & $79.3 \pm 16$ & $58.2 \pm 20.6$ \\
\hline & More than 65 years & $n$ & 232 & 230 & 225 & 227 & 232 \\
\hline & & Mean \pm SD & $56.7 \pm 19.5$ & $78.8 \pm 18.3$ & $74.7 \pm 16.3$ & $80.7 \pm 15.5$ & $60.8 \pm 20$ \\
\hline & ANOVA & $p$-value & 0.002 & 0.083 & 0.009 & 0.082 & 0.019 \\
\hline
\end{tabular}

$P H$, Physical health; SF, Social functioning; $M C$, Medical care and satisfaction; $T R$, Treatment; FLG, Fear of losing graft; ANOVA, Analysis of variance to compare; RTQ, scores between age class.

first version were moved to other more appropriate dimensions after considering the results of the ACP. The meaning of questions was not changed or modified at all in the second version of the RTQ. Each dimension was named identically to the first version of RTQ, according to the composition of its items, except for Mental Health $(\mathrm{MH})$ which was named Social Functioning (SF) because these items are essentially oriented around the patient's family, friends and social isolation.

The RTQ V2 is currently comprised of 32 items to specifically assess the HRQOL for the renal transplant recipient. Then, another PCA was performed, which showed a very good structure of the new version of the questionnaire. All items had a factor loading over the recommended threshold of 0.40 for their specific dimension, except for one item (q17: Are you satisfied with your graft?). Nevertheless, item q17 was retained due to the clinical relevance in terms of content validity and to assure a Cronbach's Alpha $\geq 0.7$ in its dimension. This structure provided better results for reliability, content validity and clinical validity. The explained variance between the first and second RTQ versions improved from $46.3 \%$ to $53.1 \%$ (an increase of $6.8 \%$ ).

All psychometric properties of RTQ V2 were satisfactory: IIC $>0.4$, IDV (\%) of $100 \%$ and Cronbach's Alpha $>0.7$ in every dimension. The acceptability was excellent with a low percentage of missing data and low floor and ceiling effects. The high psychometric properties could be related to the development of the RTQ V2 based on the first version of the RTQ. The new RTQ is shorter than the previous version and should be better accepted by patients, with a shorter average completion time $( \pm-4 \mathrm{~min}$ to $-5 \mathrm{~min})$.
Convergent validity of the RTQ scores was overall well correlated with that of the generic SF36 questionnaire.

Dimensions relative to physical aspects taken from the SF36 were correctly correlated with the ReTransQol Physical Health dimension, and high correlations were also found between both the Social Functioning dimension and the Mental Health score and ReTransQol Mental Health dimension [renamed Social Functioning (SF)]. Indeed, due to the item reduction step, the 5 items of the previous $\mathrm{MH}$ dimension of the RTQ now essentially describe a social functioning dimension.

As expected, the Medical Care dimension was uncorrelated with SF36 dimensions because it is a unique concept of our questionnaire, highlighting the need for a specific HRQOL questionnaire. In addition, strong correlations were found between the Vitality and General Health dimensions of the SF36 and with the Treatment dimension of the RTQ.

Furthermore, as we could expect, the Fear of Losing Graft dimension was correlated with the Mental Health and General Health dimensions of the SF36. All items showed a good fit to the Rasch model within each dimension, and strengthened the unidimensionality of the questionnaire.

Comparisons between different demographic subgroups confirm previous empirical data showing their variations. For example, our results confirm that women have lower QOL scores in comparison with men, in every dimension $[44,45]$. Concerning age, patients $>65$ years have a significantly lower score in the $\mathrm{PH}$ dimension, with relatively similar scores on the $\mathrm{MH}$ and TR dimensions when compared to patients aged 35-50 years, but higher scores on the $\mathrm{MC}$ and FLG dimensions compared with younger 


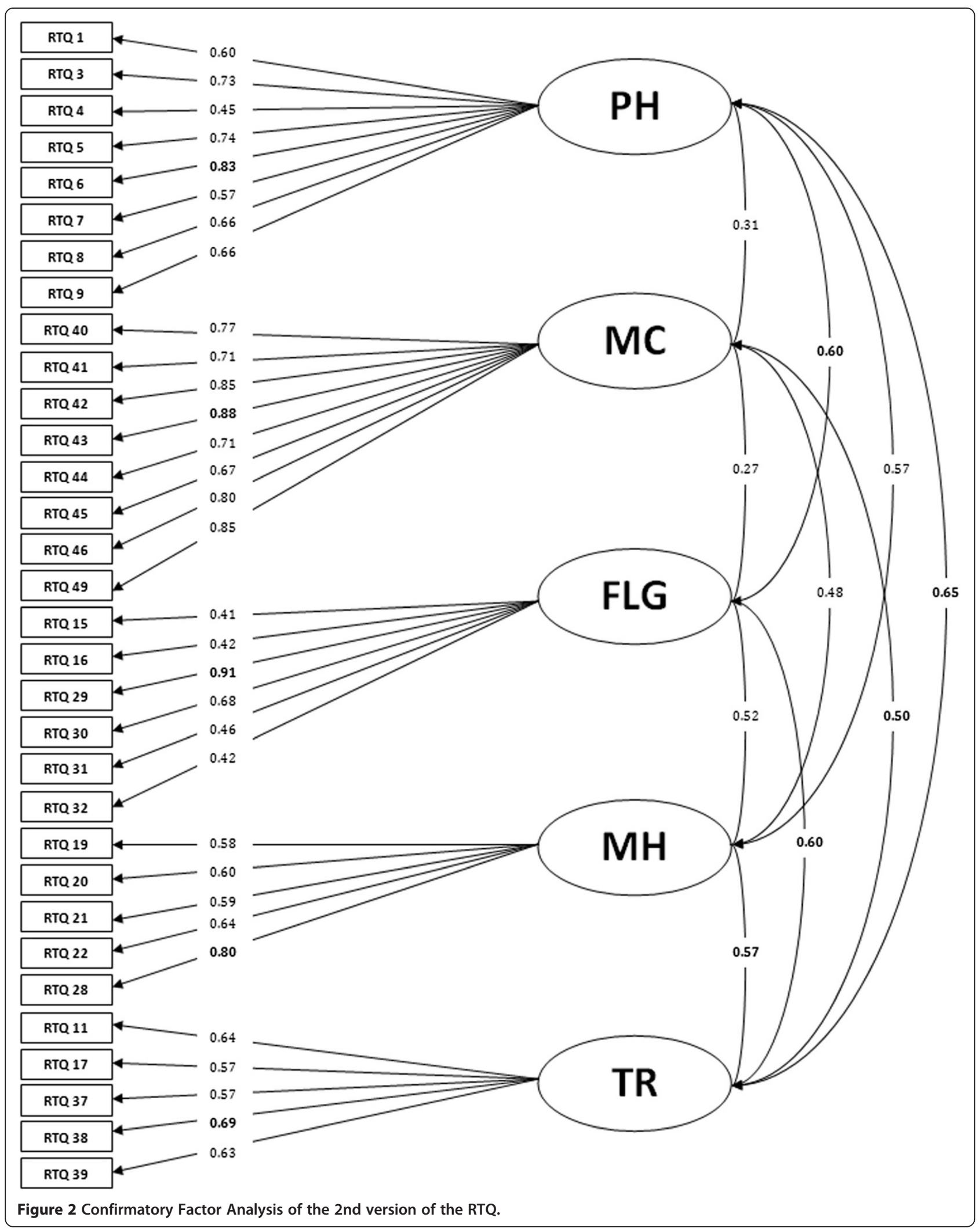


patients $(<35$ years). This may be explained by the fact that elderly patients are satisfied with medical care they receive in the hospital, less anguished to lose their graft because of their advanced age, and that they are limited due to their reduced physical capacity [46-48].

Finally, the new version of the RTQ V2 was established by a confirmatory factor analysis with a population of 1,591 RTR. Results of the CFA showed that the model converged with a good index of overall fit (GFI $>0.91)$ and confirmed the satisfactory structure of the new version of the RTQ. Moreover, the CFA showed an interesting correlation between different dimensions: PH and FLG, MC and TR, FLG and PH, FLG and TR, MH and TR, and TR and PH.

Sensitivity to change and reproducibility testing were not performed because the two samples were extracted from two cross-sectional studies. An analysis is currently underway on a French cohort of 334 patients followed over a period of one year.

Table 8 Final version of the RTQ V2

\begin{tabular}{|c|c|c|c|}
\hline Items number & Dimension affectations & Items label & Response modalities \\
\hline 1 & FLG & Are you anxious about your state of health? & \\
\hline 2 & $\mathrm{PH}$ & Have you had physical pain? & \\
\hline 3 & SF & Do you feel isolated? & All most time \\
\hline 4 & $\mathrm{PH}$ & Have you felt tired? & Most of time \\
\hline 5 & FLG & Do you think about a possible return to dialysis? & A good bit of the time \\
\hline 6 & $\mathrm{PH}$ & Do you feel energetic? & Some of the time \\
\hline 7 & FLG & $\begin{array}{c}\text { Does waiting for the results of medical tests distress } \\
\text { you or make you feel scared? }\end{array}$ & A little of the time \\
\hline 8 & $\mathrm{PH}$ & Do you engage in physical exercise? & None of time \\
\hline 9 & FLG & Do you still sometimes think about dialysis? & \\
\hline 10 & MC & $\begin{array}{l}\text { Do you feel like you are sufficiently informed about } \\
\text { the side effects of your treatments? }\end{array}$ & \\
\hline 11 & TR & Are you annoyed by the side effects of treatment? & \\
\hline 12 & $M C$ & Are you satisfied by your medical follow-up? & \\
\hline 13 & FLG & Do you often think about your graft? & \\
\hline 14 & TR & Are you satisfied with your graft? & \\
\hline 15 & SF & Does your family offer you moral support? & \\
\hline 16 & MC & Do you have trust in the prescribed treatments? & \\
\hline 17 & TR & $\begin{array}{c}\text { Are you scared of the possible side effects of the } \\
\text { anti-rejection treatment? }\end{array}$ & \\
\hline 18 & SF & Do you feel close to your friends? & Not at all \\
\hline 19 & TR & Is taking medications a constraint for you? & A little bit \\
\hline 20 & MC & Do you feel supported by the medical team? & Moderately \\
\hline 21 & TR & Are your doctor's orders restrictive? & Quite a bit \\
\hline 22 & MC & Do you trust your nephrologist? & Extremely \\
\hline 23 & SF & Do you feel misunderstood by the people around you? & \\
\hline 24 & $M C$ & Do you feel sufficiently informed by your nephrologist? & \\
\hline 25 & SF & Has your family accepted your illness? & \\
\hline 26 & $M C$ & $\begin{array}{l}\text { Do you feel like you are sufficiently informed about } \\
\text { complications of the graft? }\end{array}$ & \\
\hline 27 & FLG & Have you been able to forget that you received a graft? & \\
\hline 28 & $M C$ & Are you satisfied by your nephrologist's ability to listen? & \\
\hline 29 & $\mathrm{PH}$ & You are as well as anyone else & Definitely agree \\
\hline 30 & $\mathrm{PH}$ & You have stopped doing certain things. & Mostly agree \\
\hline 31 & $\mathrm{PH}$ & You feel autonomous. & Not agree not disagree \\
\hline \multirow[t]{2}{*}{32} & $\mathrm{PH}$ & You can do your housework and errands by yourself. & Mostly disagree \\
\hline & & & Definitely disagree \\
\hline
\end{tabular}


Although further studies may be needed to test the questionnaire in various cultural contexts, the RTQ V2 (Table 8 ) should provide a valid measure to assess the HRQOL of RTR.

\section{Conclusion}

This study reported the different phases of analysis, adaptation and validation of the RTQ and the resulting new version: the RTQ V2 (Table 8). It is a HRQOL questionnaire for renal transplant recipients which was developed and improved in response to a lack of any validated instrument for these patients in the French language. The quality of life for patients with chronic diseases has become a public health priority in France, especially since the new Public Health Law.

Psychometric properties allow this new version of the questionnaire to be used to assess different specific dimensions for the renal transplant population, more effectively than previously possible. We envision continuing this work by the follow-up of a prospective cohort to study the sensitivity to change, reproducibility and clinically significant threshold. Furthermore, we plan to adapt and validate this new version of the questionnaire in English.

\section{Competing interests}

The authors declare that they have no competing interests.

\section{Authors' contributions}

DB performed statistical analysis, analyzed and interpreted the data, collected some data and drafted the manuscript. SG conceived the study and its design, coordinated the data management, revised the manuscript critically; EJ participated in the design of the study, collected the data and performed the statistical analysis BD participated in the design of the study, collected medical data and participated to the interpretation of data. CJ et SB conceived the study and its design, coordinated the data management, revised the manuscript critically for important intellectual content and have given final approval of the version to be published. All authors read and approved the final manuscript.

\section{Author details}

${ }^{1}$ Faculté de Médecine, Laboratoire de Santé Publique, Université Aix-Marseille, Marseille EA 3279, France. ${ }^{2} \mathrm{CHU}$ Marseille, Service Santé Publique et Information Médicale, Marseille, France. ${ }^{3} \mathrm{CHU}$ Marseille, Centre de Néphrologie et de Transplantation Rénale, Marseille, France. ${ }^{4}$ Agence de la Biomédecine, Paris, France. ${ }^{5} \mathrm{CHU}$ Nancy, Epidémiologie et Evaluation Cliniques, Nancy, France. ${ }^{6}$ Université de Lorraine, Université Paris Descartes, Apemac, Nancy EA 4360, France.

Received: 2 July 2013 Accepted: 14 August 2013 Published: 30 August 2013

\section{References}

1. Molnar-Varga M, Molnar MZ, Szeifert L, Kovacs AZ, Kelemen A, Becze A, Laszlo G, Szentkiralyi A, Czira ME, Mucsi I, Novak M: Health-related quality of life and clinical outcomes in kidney transplant recipients. Am J Kidney Dis 2011, 58:444-452.

2. Nilsson M, Forsberg A, Bäckman L, Lennerling A, Persson L-O: The perceived threat of the risk for graft rejection and health-related quality of life among organ transplant recipients. J Clin Nurs 2011, 20:274-282.

3. Avramovic M, Stefanovic V: Health-related quality of life in different stages of renal failure. Artif Organs 2012, 36:581-589.
4. Maglakelidze N, Pantsulaia T, Tchokhonelidze I, Managadze L, Chkhotua A: Assessment of health-related quality of life in renal transplant recipients and dialysis patients. Transplant Proc 2011, 43:376-379.

5. Jofré R, López-Gómez JM, Moreno F, Sanz-Guajardo D, Valderrábano F: Changes in quality of life after renal transplantation. Am J Kidney Dis 1998, 32:93-100.

6. Chanliau J, Kessler M: La dialyse péritonéale dans le parcours de soins de I'insuffisant rénal : aspects financiers. Néphrol Thérapeutique 2011, 7:32-37.

7. De Abreu MM, Walker DR, Sesso RC, Ferraz MB: A cost evaluation of peritoneal dialysis and hemodialysis in the treatment of end-stage renal disease in Sao Paulo, Brazil. Perit Dial Int J Int Soc Perit Dial juin 2013, 33(3):304-315.

8. Suja A, Anju R, Anju V, Neethu J, Peeyush P, Saraswathy R: Economic evaluation of end stage renal disease patients undergoing hemodialysis. J Pharm Bioallied Sci. 2012, 4:107-111.

9. Blotière $\mathrm{P}-\mathrm{O}$, Tuppin $\mathrm{P}$, Weill $\mathrm{A}$, Ricordeau $\mathrm{P}$, Allemand $\mathrm{H}$ : Coût de la prise en charge de I'IRCT en France en 2007 et impact potentiel d'une augmentation du recours à la dialyse péritonéale et à la greffe. Néphrol Thérapeutique 2010, 6:240-247.

10. Fresenius Medical Care: ESRD Patients in 2011 A Global Perspective; 2012. http:// www.vision-fmc.com/files/download/ESRD/ESRD_Patients_in_2011.pdf.

11. REIN: rapport annuel; 2010. http://www.agence-biomedecine.fr/IMG/pdf/ 2012_rapport_annuel_rein.pdf.

12. Djamali A, Samaniego M, Muth B, Muehrer R, Hofmann RM, Pirsch J, Howard A, Mourad G, Becker BN: Medical care of kidney transplant recipients after the first posttransplant year. Clin J Am Soc Nephrol 2006, 1:623-640.

13. Pauly RP: Survival comparison between intensive hemodialysis and transplantation in the context of the existing literature surrounding nocturnal and short-daily hemodialysis. Nephrol Dial Transplant 2013, 28:44-47.

14. Wolfe RA, Ashby VB, Milford EL, Ojo AO, Ettenger RE, Agodoa LY, Held PJ, Port FK: Comparison of mortality in all patients on dialysis, patients on dialysis awaiting transplantation, and recipients of a first cadaveric transplant. N Engl J Med 1999, 341:1725-1730.

15. Abecassis M, Bartlett ST, Collins AJ, Davis CL, Delmonico FL, Friedewald JJ, Hays R, Howard A, Jones E, Leichtman AB, Merion RM, Metzger RA, Pradel F, Schweitzer EJ, Velez RL, Gaston RS: Kidney transplantation as primary therapy for End-stage renal disease: a national kidney foundation/kidney disease outcomes quality initiative (NKF/KDOQI ${ }^{\mathrm{TM}}$ ) conference. CJASN. 2008, 3:471-480.

16. Muehrer RJ, Becker BN: Life after transplantation: new transitions in quality of life and psychological distress. Semin Dial 2005, 18:124-131.

17. Muehrer RJ, Becker BN: PSYCHOSOCIAL FACTORS IN PATIENTS WITH CHRONIC KIDNEY DISEASE: life after transplantation: New transitions in quality of life and psychological distress. Sem Dialysis 2005, 18:124-131.

18. Rebollo P, González MP, Bobes J, Saiz P, Ortega F: [Interpretation of healthrelated quality of life of patients on replacement therapy in end-stage renal disease]. Nefrologia 2000, 20:431-439.

19. Fiebiger W, Mitterbauer C, Oberbauer R: Health-related quality of life outcomes after kidney transplantation. Health Qual Life Outcomes 2004, 2:2.

20. Lee AJ, Morgan CL, Conway P, Currie CJ: Characterisation and comparison of health-related quality of life for patients with renal failure. Curr Med Res Opin 2005, 21:1777-1783.

21. Maglakelidze N, Pantsulaia T, Managadze L, Chkhotua A: Assessment of health-related quality of life in living kidney donors. Transplant Proc 2011, 43:373-375.

22. Gentile S, Beauger D, Speyer E, Jouve E, Dussol B, Jacquelinet $C$, et al: Factors associated with health-related quality of life in renal transplant recipients: results of a national survey in France. Health Qual Life Outcomes 30 mai 2013, 11(1):88.

23. Gentile S, Delarozière JC, Fernandez C, Tardieu S, Devictor B, Dussol B, Daurès JP, Berland Y, Sambuc R: Review of quality of life instruments used in end-stage renal disease. Nephrologie 2003, 24:293-301.

24. Parfrey PS, Vavasour H, Bullock M, Henry S, Harnett JD, Gault MH: Development of a health questionnaire specific for end-stage renal disease. Nephron 1989, 52:20-28.

25. Fujisawa M, Ichikawa Y, Yoshiya K, Isotani S, Higuchi A, Nagano S, Arakawa S, Hamami G, Matsumoto O, Kamidono S: Assessment of health-related quality of life in renal transplant and hemodialysis patients using the SF-36 health survey. Urology 2000, 56:201-206.

26. Wight JP, Edwards L, Brazier J, Walters S, Payne JN, Brown CB: The SF36 as an outcome measure of services for end stage renal failure. Qual Health Care 1998, 7:209-221. 
27. Telles-Correia D, Barbosa A, Mega I: [Quality of life and transplantation]. Acta Med Port 2010, 23:1091-1100.

28. Gentile S, Jouve E, Dussol B, Moal V, Berland Y, Sambuc R: Development and validation of a French patient-based health-related quality of life instrument in kidney transplant: the ReTransQoL. Health Qual Life Outcomes 2008, 6:78.

29. Gentile S, Boini S, Germain L, Jacquelinet C: Qualité de vie des patients dialysés et transplantés rénaux: résultats de deux enquêtes multirégionales, France. Bull Epidemiol Hebd. 2010, 9-10:92-96.

30. Agence de Biomédecine: Renal Epidemiology and Information Network: 2008 REIN report. Nephrol Ther 2010, 6(Suppl 2):S25-183.

31. Ware JE Jr, Sherbourne CD: The MOS 36-item short-form health survey (SF-36). I. Conceptual framework and item selection. Med Care 1992, 30:473-483

32. Hair JF Jr, Black WC, Babin BJ, Anderson RE: Multivariate Data Analysis: A Global Perspective. Seventh edth edition. Upper Saddle River, New Jersey: Pearson: 2010. ISBN-13: 978-0-13-515309-3.

33. Kaiser HF: The varimax criterion for analytic rotation in factor analysis. Psychometrika 1958, 23:187-200.

34. Campbell DT, Fiske DW: Convergent and discriminant validation by the multitrait-multimethod matrix. Psychol Bull 1959, 56:81-105.

35. Carey RG, Seibert JH: A patient survey system to measure quality improvement: questionnaire reliability and validity. Med Care 1993, 31:834-845.

36. Cronbach $\sqcup$ : Coefficient alpha and the internal structure of tests. Psychometrika 1951, 16:297-334

37. Cortina JM: What is coefficient alpha? An examination of theory and applications. J App Psychol 1993, 78:98-104.

38. Masters GN: A rasch model for partial credit scoring. Psychometrika 1982, 47:149-174.

39. Masters GN: The analysis of partial credit scoring. App Measure Educ 1988 1:279-297.

40. Jöreskog KG: A general approach to confirmatory maximum likelihood factor analysis. Psychometrika 1969, 34:183-202.

41. Hu L, Bentler PM: Cutoff criteria for fit indexes in covariance structure analysis: Conventional criteria versus new alternatives. Struct Equa Model Multidisciplin J 1999, 6:1-55

42. Thompson B: Exploratory and confirmatory factor analysis: understanding concepts and applications. Washington, DC, US: American Psychological Association; 2004

43. Baumgartner $\mathrm{H}$, Homburg $\mathrm{C}$ : Applications of structural equation modeling in marketing and consumer research: A review. Int J Res Marketing 1996, 13:139-161

44. Lazzaretti CT, Carvalho JGR, Mulinari RA, Rasia JM: Kidney transplantation improves the multidimensional quality of life. Transplant Proc 2004, 36:872-873.

45. Bohlke M, Marini SS, Rocha M, Terhorst L, Gomes RH, Barcellos FC, Irigoyen MCC, Sesso R: Factors associated with health-related quality of life after successful kidney transplantation: a population-based study. Qual Life Res 2009, 18:1185-1193.

46. Valderrábano F, Jofre R, López-Gómez JM: Quality of life in end-stage renal disease patients. Am J Kidney Dis 2001, 38:443-464.

47. Rosenberger J, Van Dijk JP, Nagyova I, Zezula I, Geckova AM, Roland R, Van den Heuvel WJA, Groothoff JW: Predictors of perceived health status in patients after kidney transplantation. Transplantation 2006, 81:1306-1310.

48. Rebollo P, Ortega F, Baltar JM, Díaz-Corte C, Navascués RA, Naves M, Ureña A, Badía X, Alvarez-Ude F, Alvarez-Grande J: Health-related quality of life (HRQOL) in end stage renal disease (ESRD) patients over 65 years. Geriatr Nephrol Urol 1998, 8:85-94.

doi:10.1186/1477-7525-11-148

Cite this article as: Beauger et al:: Analysis, evaluation and adaptation of the ReTransQoL: a specific quality of life questionnaire for renal transplant recipients. Health and Quality of Life Outcomes 2013 11:148

\section{Submit your next manuscript to BioMed Central and take full advantage of:}

- Convenient online submission

- Thorough peer review

- No space constraints or color figure charges

- Immediate publication on acceptance

- Inclusion in PubMed, CAS, Scopus and Google Scholar

- Research which is freely available for redistribution

Submit your manuscript at www.biomedcentral.com/submit
Biomed Central 